\title{
Biodiversity management strategies for mountains: active or passive management practice?
}

\section{Zoltán Kun}

Keywords: wilderness management, protected areas, European Parliament, PAN Parks

\section{Abstract}

Wilderness management practices are increasingly seen as a tool to maintain Europe's unique natural heritage including mountain habitats. The countless benefits of non-intervention management are becoming more and more apparent in a variety of different habitats across Europe, as well as the amount of work required for the proper implementation of this approach. Following the European Parliament resolution on wilderness, PAN Parks Foundation argues for the expansion of wilderness management in mountain areas. The sustainable tourism development process helps to ensure that tourism provides real benefits for the rural communities in and around the protected areas and at the same time reduces the pressure caused by tourism on the park.

\section{Introduction}

During the recent Euromontana conference in Lillehammer, Norway (September 2010), some participants argued for lobbying to get more subsidies to maintain traditional land-use practices throughout European mountains. The argument was mainly linked to agriculture land use, extensive farming. People referred to the fact that most mountain grasslands are secondary vegetation formations that require a certain level of human maintenance for their continued existence. The countless benefits of non-intervention management, however, are becoming more and more apparent in a variety of different habitats across Europe, as well as the amount of work required for the proper implementation of this approach. There are also organizations that have always been dedicated to promoting wilderness management, such as the PAN Parks Foundation.

Considering the potential of applying this approach, the $3^{\text {rd }}$ Global Biodiversity Outlook report mentioned the opportunity for "rewilding landscapes from farmland abandonment in some regions - particularly in Europe, where about $200000 \mathrm{~km}^{2}$ of land are expected to be freed up by 2050. Ecological restoration and reintroduction of large herbivores and carnivores will be important in creating self-sustaining ecosystems with minimal need for further human intervention." (Secretariat of the Convention on Biological Diversity (2010) Global Biodiversity Outlook 3 Montréal). This expectation of rewilding large proportions of land has great importance for mountain regions. In EU member states, mountains account for a greater proportion of a country's natural and environmental assets than non-mountainous areas. In terms of wilderness, the greatest proportion and area in Europe is found in the Nordic mountains. Elsewhere, only Spain has more than $10000 \mathrm{~km}^{2}$ of mountain wilderness. Of the total area designated as Natura 2000 sites, $43 \%$ is mountainous, compared to $29 \%$ for the EU as a whole. These sites cover $14 \%$ of the mountain areas

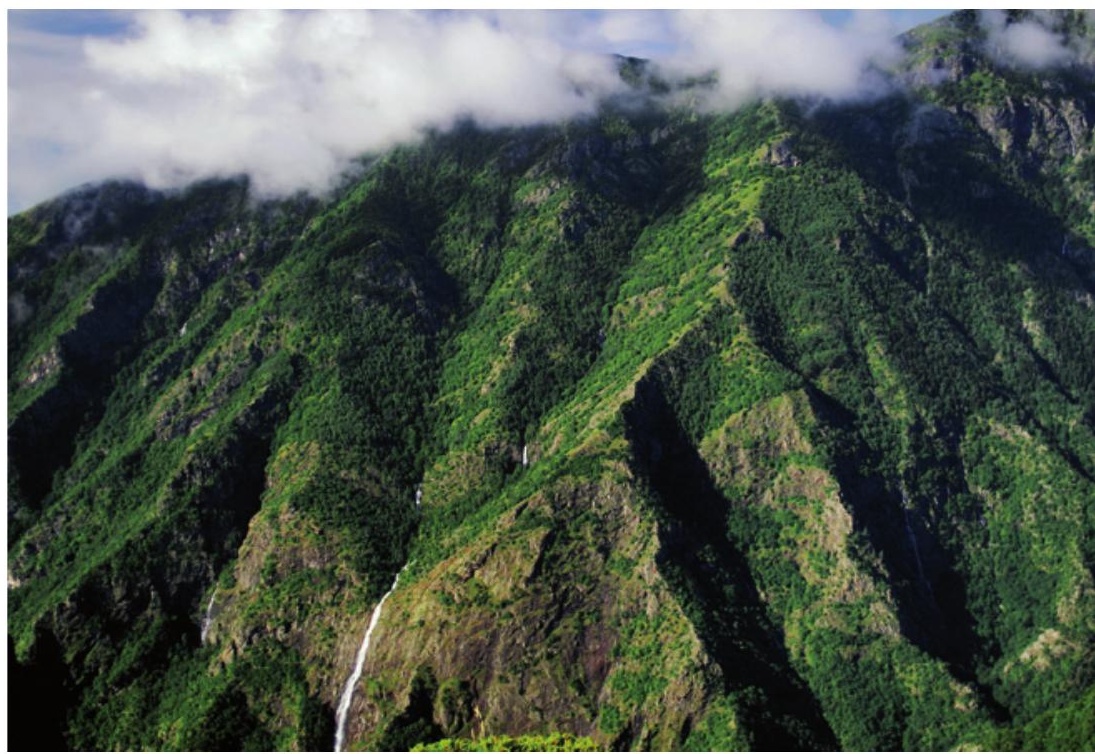

Specific parts of Europe's mountains have been protected to ensure continued provision of ecosystem services. A large proportion of the remaining European wilderness areas can be found in mountain areas like Central Balkan National Park (NP), Bulgaria. (C) Petar Paunchev

of the EU (Europe's ecological backbone: recognising the true value of our mountains (EEA 2010)).

\section{Biodiversity decline}

Despite the ambitious target assumed by the world's governments of reducing the rate of biodiversity loss by 2010 , biodiversity continues to decline (Butchart et al. 2010) and scenarios for the future show that the window of opportunity to reverse biodiversity loss is closing (Pereira et al. 2010). After failing to meet the 2010 biodiversity target, the parties to the Convention on Biological Diversity in Nagoya, Japan, have just agreed a new set of ambitious targets for 2020. These targets include increasing protected area coverage from $12 \%$ of the land surface to $17 \%$ or to ensure that all areas under forestry become managed sustain- 


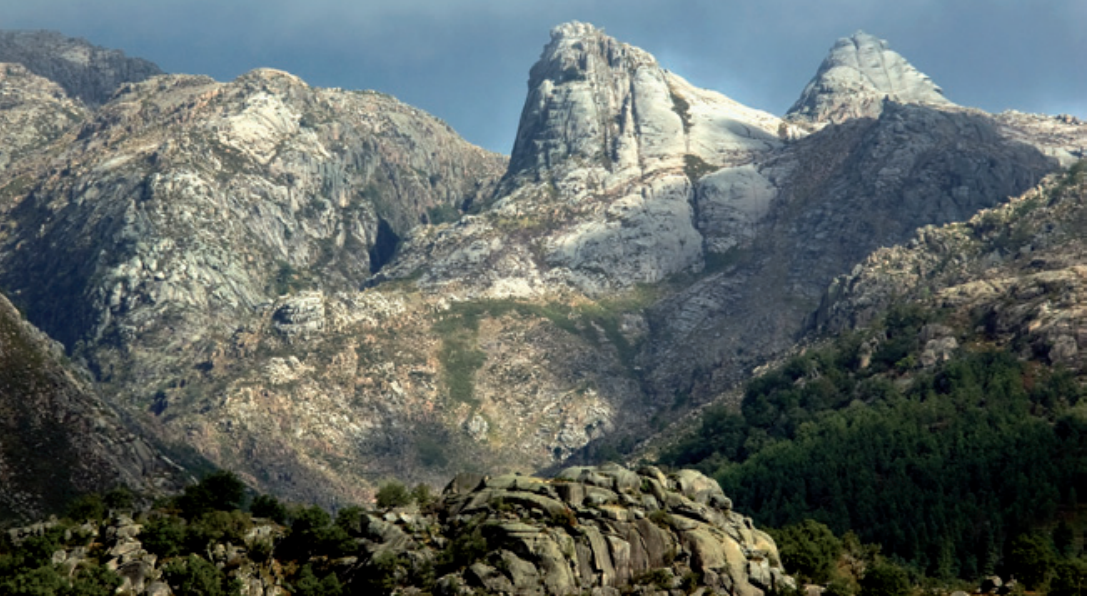

In order to promote the concept of wilderness and provide best-practice examples, the PAN Parks Foundation is creating a network of the large well-managed protected areas with wilderness areas. Protected areas like Peneda-Gerês NP, Portugal, also provide a unique experience for visitors. (C) PGNP Archives

ably. However, the effectiveness of these targets in reversing biodiversity loss will depend on how they will be implemented by governments, local decisionmakers and the private sector. Particularly important will be how society values the different benefits arising from biodiversity and how the valuation of those benefits will be integrated into public and private decision-making (Rands et al. 2010).

Over the past decade, two major studies on the benefits of biodiversity have been conducted: the Millennium Ecosystem Assessment (MA) (Duraiappah et al. 2005), and The Economics of Ecosystems and Biodiversity (TEEB) (TEEB 2010). The MA developed a conceptual approach for the benefits of biodiversity based on the concept of ecosystem services. It proposed that there are four categories or ecosystem services: provisioning services are the products that we obtain from ecosystems, such as food and timber;

regulating services are the benefits we obtain from the regulation of ecosystem processes, such as climate regulation and flood protection;

cultural services are non-material benefits that people obtain from ecosystems, such as existence values and recreation value;

supporting services are the ecological functions, such as nutrient cycling, that support the delivery of all other ecosystem services.

The MA found that our economies and policies tend to value and prioritize provisioning services to the detriment of regulation, and, to a lesser extent, cultural services. The TEEB took the analysis of the benefits of biodiversity a step further by reviewing the main methods of economic valuation of ecosystem services and by assessing the economic impacts of biodiversity loss at different scales. The TEEB developed a tiered approach with three components: recognizing value, demonstrating value and capturing value. The TEEB results suggest that in many cases, recognizing the non-use value of a habitat or a species is sufficient to ensure its conservation, without the need to demonstrate its use value or to capture such value in economic incentives (e.g. ecosystem service payments) or price signals (e.g. product certification). Such non-use values include the existence or the option values associated with the maintenance of certain species or habitats. Despite the significant progress made by the MA and TEEB in developing a biodiversity valuation framework, we still lack a detailed assessment of the effectiveness of different biodiversity conservation strategies and how they relate to ecosystem services. There is a need to fill that gap across temporal and spatial scales by looking at two extremes of biodiversity management approaches, passive management versus active management, and their linkages to a range of ecosystem services, including existence values.

Passive management emphasizes the protection of wilderness and its expansion through rewilding of abandoned lands, while active management promotes the maintenance of cultural landscapes and associated species and habitat diversity through farming, grazing, forestry and other activities.

The vulnerability of each biodiversity strategy to key environmental challenges such as food security and climate change deserves particular attention. The implications of each strategy for the production of each ecosystem service need to be examined. Such an examination should be based on the development of future land-use scenarios which integrate socio-economic dynamics driving land-use change with biodiversity strategies. There are also the reverse links of the implications of maximizing a given ecosystem service for different biodiversity metrics such as species diversity and wilderness. These linkages should also be examined across spatial scales, from the European scale to the local scale.

The worldwide biodiversity decline calls for more effective conservation efforts (Butchart et al. 2010; Hoffmann et al. 2010). In situ conservation, particularly through protected areas, is arguably the most effective conservation strategy (Rodrigues et al. 2004). However, biodiversity (the sheer variety of life, including all species of plants, animals, microorganisms and the ecosystems and ecological processes which they shape; (Gaston 1996)) is a multidimensional concept that cannot be quantified using a simple measure. Instead, a diversity of metrics is typically used to measure different aspects of biodiversity, including species diversity, habitat diversity and ecosystem intactness (Gaston 1996; Scholes \& Biggs 2005; Butchart et al. 2010). Whether the best strategy for in situ management is a proactive or a reactive approach depends on the context, including the nature of the particular biodiversity values that are being conserved.

On a global scale, some of the regions of the world with the highest species diversity are also regions of high human impact (Myers et al. 2000) and these re- 
quire urgent conservation action (Brooks et al. 2006), typically through a more active type of management because in many cases the important habitats persist as small fragments within a matrix of human occupation (e.g. Madagascar, Philippines). In contrast, expansive ecosystems which are still largely intact require a proactive conservation strategy to ensure that they remain as wilderness areas, generally through passive management (Brooks et al. 2006). Conservation arguments valuing the former have typically emphasized their importance for the conservation of global species diversity by preventing species extinctions (Myers et al. 2000; Brooks et al. 2006) while calls for conservation of the former have focused on their value as wilderness areas for the aesthetic and intellectual contemplation of nature, for the maintenance of intact species assemblages and ecosystem processes and for the provision of broader ecosystem services such as climate regulation (e.g. Kareiva et al. 2003). This dichotomy is somewhat artificial: wilderness areas may be fundamental for global species conservation (Mittermeier et al. 2003) while highly impacted hotspots may be important for the provision of ecosystem services (Turner et al. 2007).

Within Europe, conservation strategies are further complicated by the spatial extent and temporal duration of the human occupation. On the one hand, areas of traditional extensive agriculture are considered fundamental to the conservation of many species and habitats (e.g. of steppe birds in southern Portugal; Alonso et al. 2003). Changing socio-economic conditions mean that the maintenance of these habitats now typically requires intensive habitat management to mimic what was achieved with traditional human occupation (Catry et al. 2009). On the other hand, true wilderness areas - areas still maintaining relatively complex ecological assemblages, including predators - are extremely rare (Morrison et al. 2007) and under great threat. Increasing urbanization and a reduction of hunting pressure in some regions result in a spatial reorganization of human occupation, providing an opportunity for new wilderness areas to emerge (as testified for instance by the natural expansion of wolf populations in the Alps and the Apennines; Fabbri et al. 2007). However, land abandonment is often associated with the emergence of habitats and species assemblages considered of less conservation interest, at least in the short term (Moreira \& Russo 2007).

\section{Wilderness and mountains}

The concept of wilderness occupies one extreme end of the environmental modification spectrum as defined by Nash (1967) and adapted subsequently by others for mapping human modification of natural ecosystems (see UNEP Globio GEO-3 Project, 2002) and the concept of the wilderness continuum (Carver \& Fritz 1996). Emphasis on the need to conserve wilderness areas has been mounting internationally (e.g.

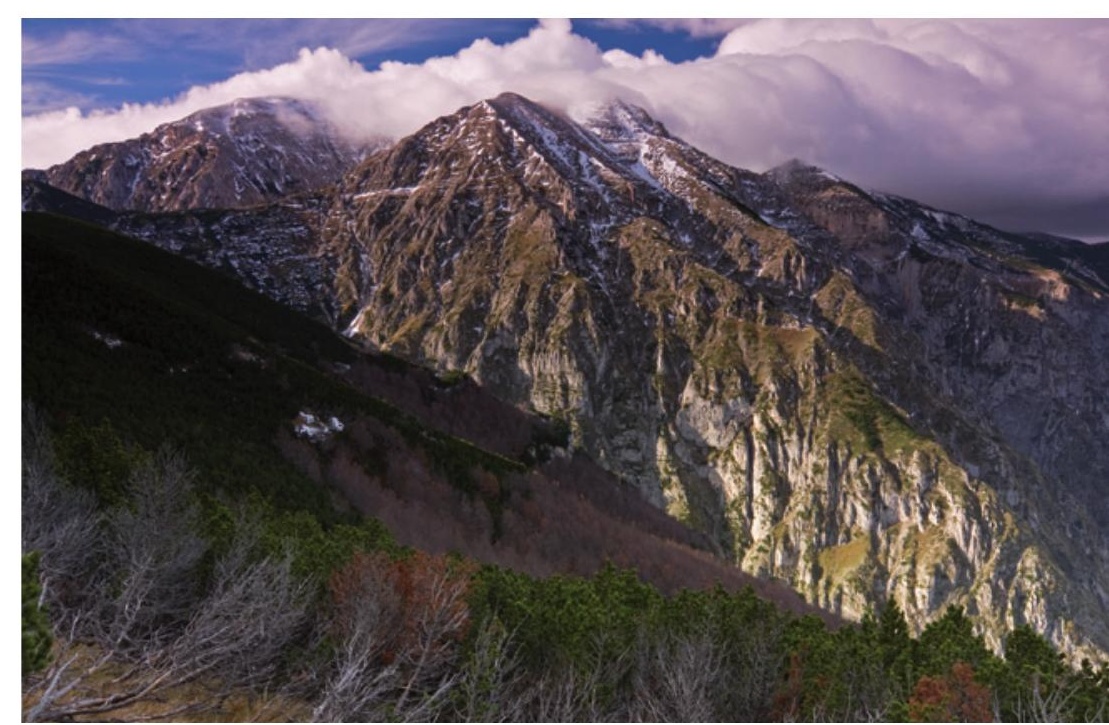

Members of the PAN Parks network like Majella NP, Italy, can serve as examples and encourage countries and organizations throughout Europe to improve wilderness protection by applying passive management approaches. The increasing size of mountain wilderness and wild lands will also further support halting biodiversity loss in Europe. (C) Bruno D'Amicis

WILD9 congress, Merida, Mexico, 2009; Mittermeier et al. 2003) and at European level. Within Europe itself, wilderness is the focus of several organizations including the Wild Europe Initiative, PAN Parks and the Wild Europe Field Programme (Rewilding Europe). Europe has already developed the world's largest network of biodiversity conservation focus areas under the Natura 2000 network and IUCN Category 1a (Strict Nature Preserve) and 1b (Wilderness Area) protected areas already cover some of Europe's wildernesses. In addition, wilderness may also be seen as a special case within the European Landscape Convention. Despite this, there is still much debate and disagreement over the exact definition of wilderness and what criteria ought to be applied in defining its boundaries and generating accurate and timely quantitative assessments of its value in terms of biodiversity and human benefit.

The European Parliament resolution on Wilderness (INI/2008/2210) and the Message from Prague state the need to "define wilderness, addressing aspects such as ecosystem services, conservation value, climate change and sustainable use" and to finalize "a definition of wilderness and wild areas, taking into account the globally agreed definitions, criteria and characteristics and the continum of natural habitats and ecological processes, the range of ecological and cultural interpretations of these terms and their application in different parts of Europe".

Wilderness can be broadly defined in terms of perceived wilderness, which consists of the human experience of wild and remote landscapes and ecological wilderness, which includes pristine and natural habitat areas (Carver et al. 2002).

For centuries, specific parts of Europe's mountains have been protected to ensure continued provision of ecosystem services. It is believed that a large proportion of Europe's wilderness can be found in moun- 


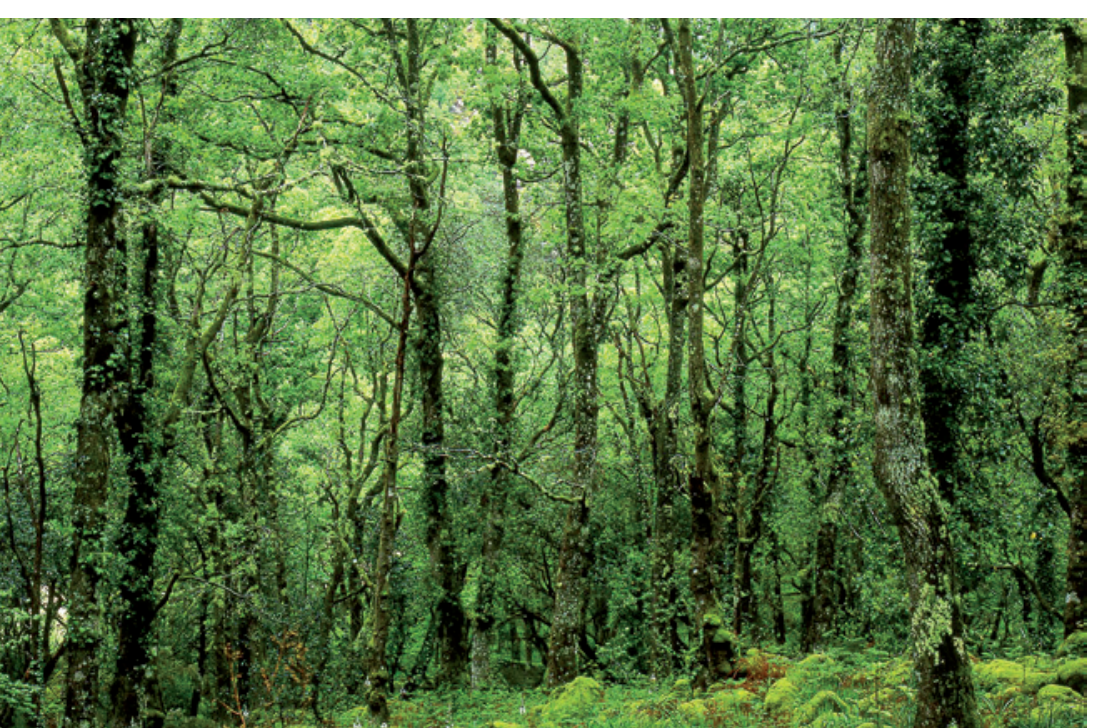

Wilderness management practices are seen widely as a tool to maintain Europe's natural heritage including mountain habitats such as Peneda-Gerês NP, Portugal. (C) PGNP Archives

tain areas (EEA 2010). Therefore the management of Europe's wilderness areas has significant implications for policy in relation to mountain regions. In February 2009, with an overwhelming majority, the European Parliament passed a resolution calling for increased protection of wilderness areas in Europe. Subsequently in 2009, the Czech Presidency and the European Commission hosted a conference in Prague organized by the Wild Europe partnership on the theme of Wilderness and Large Natural Habitat Areas in Europe. Over 240 delegates helped draft an agreement to further promote a coordinated strategy to protect and restore Europe's wilderness and wild areas.

The so-called Agenda for Europe's Wilderness (a.k.a. the Prague Message) includes the following elements:

agreeing on the definition and location of wild and nearly wild areas;

determining the contribution that such areas can make to halting biodiversity loss and supporting Natura 2000;

recommendations for improved protection of such areas within the existing legal framework;

review of opportunities for restoring large natural habitat areas;

proposals for more effective support for such restoration;

identifying best-practice examples for non-intervention and restoration management;

defining the value of low-impact economic, social and environmental benefits from wild areas.

\section{The PAN Parks concept}

From a conservation perspective, the PAN Parks Foundation (http://www.panparks.org), the only panEuropean organization focusing on the protection of wilderness areas, occupies a unique niche in terms of its attempt to redefine and develop a concept of wilderness conservation in Europe, one of the most high- ly developed areas in the world. In order to promote the concept of wilderness and provide best-practice examples, the Foundation is creating a network of the large well-managed protected areas with wilderness areas also providing a unique experience for visitors. In 2010, there were already eleven PAN Parks throughout Europe, stretching from the Arctic Circle to the Mediterranean and including several mountainous areas. PAN Parks applies a truly integrated approach combining wilderness protection and sustainable tourism development aiming to turn tourism from a threat into an opportunity for conservation.

PAN Parks provides an effective third-party verification system under the WCPA (World Commission on Protected Areas) Framework for Management Effectiveness. It sets an important benchmark for high standards in protected area management. The certification is based on verification carried out by independent experts in accordance with PAN Parks quality standards. There are five PAN Parks principles covering relevant wilderness protection, social, economic and cultural aspects. Principles allow for objective verification and transparency. The verification procedure has three main elements: verification of the protected area, its sustainable tourism strategy and the local business partners.

The sustainable tourism development process helps to ensure that tourism provides real benefits for the rural communities in and around the protected areas and at the same time reduces the pressure caused by tourism on the park. However, without the genuine support of local communities, the task of nature conservation is pointless. The sustainable tourism development strategy of PAN Parks is developed through a collaborative process between park managers and all relevant local stakeholders. The sustainable tourism development strategy is a key to ensuring that tourism supports conservation and to guaranteeing that tourism is not introduced in sensitive areas.

Local tourism-related businesses can also undergo a certification process ensuring that the business is working in harmony with the park management. This helps those involved to achieve real improvements and gives them a business advantage. It also encourages local communities and businesses to get involved and raises their awareness of the real value of wilderness. This integrated approach is the key to effective management of protected areas and is becoming rapidly recognized as a model of best practice.

PAN Parks can serve as an example and will encourage countries and organizations throughout Europe to improve protection of wilderness by applying passive management approaches also in mountainous areas. Biodiversity continues to decline in Europe, but some species and ecosystems are recovering. European states are committed to halting the loss of biodiversity and the increasing size of mountain wilderness and wild lands will contribute further to halting biodiversity loss in Europe. 


\section{References}

Alonso, J., C. Palacin \& C. Martin 2003. Status and recent trends of the great bustard (Otis tarda) population in the Iberian peninsula. Biological Conservation 110: 185-195.

Brooks, T.M., R.A. Mittermeier, G.A.B. da Fonseca, J. Gerlach, M. Hoffmann, J.F. Lamoreux, C.G. Mittermeier, J.D. Pilgrim \& A.S.L. Rodrigues. 2006. Global Biodiversity Conservation Priorities. Science 313: 58-61.

Butchart, S.H.M., M. Walpole, B. Collen, A. van Strien, J.P.W. Scharlemann, R.E.A. Almond et al. 2010. Global Biodiversity: Indicators of Recent Declines. Science 328: 1164-1168.

Carver, S. \& S. Fritz 1996. Mapping the wilderness continuum. Proceedings of the GIS Research UK.

Carver, S., A.J. Evans \& S. Fritz 2002. Wilderness attribute mapping in the United Kingdom. International Journal of Wilderness 8: 24-29.

Catry, I., R. Alcazar, A.M.A. Franco \& W.J. Sutherland 2009. Identifying the effectiveness and constraints of conservation interventions: A case study of the endangered lesser kestrel. Biological Conservation 142: 2782-2791.

EEA, Copenhagen 2010. Europe's ecological backbone: recognising the true value of our mountains. EEA Report 6.

Fabbri, E., C. Miquel, V. Lucchini, A. Santini, R. Caniglia, C. Duchamp et al. 2007. From the Apennines to the Alps: colonization genetics of the naturally expanding Italian wolf (Canis lupus) population. Molecular Ecology 16: 1661-1671.

Gaston, K. 1996. Biodiversity - a Biology of Numbers and Difference.

Secretariat of the Convention on Biological Diversity 2010. Global Biodiversity Outlook 3.

Hoffmann, M., C. Hilton-Taylor, A. Angulo, M. Bohm, T.M. Brooks, S.H.M. Butchart et al. 2010. The impact of conservation on the status of the world's vertebrates. Science 330: 1503-1509.

Kareiva, P. \& M. Marvier 2003. Conserving Biodiversity Coldspots. American Scientist 91: 344-351.

Mittermeier, R.A., C.G. Mittermeier, T.M. Brooks, J.D. Pilgrim, W.R. Konstant, G.A.B. da Fonseca et al. 2003. Wilderness and biodiversity conservation. Proceedings of the National Academy of Sciences of the United States of America 100: 10309-10313.

Moreira, F. \& D. Russo 2007. Modelling the impact of agricultural abandonment and wildfires on vertebrate diversity in Mediterranean Europe. Landscape Ecology 22: 1461-1476.

Morrison, J.C., W. Sechrest, E. Dinerstein, D.S. Wilcove \& J.F. Lamoreux 2007. Persistence of large mammal faunas as indicators of global human impacts. Journal of Mammalogy 88: 1363-1380.

Myers, N., R. Mittermeier, C. Mittermeier, G. Fonseca \& J. Kent 2000. Biodiversity hotspots for conservation priorities. Nature 403: 853-858.
Pereira, H.M., P.W. Leadley, V. Proenca, R. Alkemade, J.P.W. Scharlemann, J.F. Fernandez-Manjarreset et al. 2010. Scenarios for Global Biodiversity in the $21^{\text {st }}$ Century. Science 330: 1496-1501.

Rands, M.R.W., W.M. Adams, L. Bennun, S.H.M. Butchart, A. Clements, D. Coomes et al. 2010. Biodiversity Conservation: Challenges Beyond 2010. Science 329: 1298-1303.

Rodrigues, A.S.L., S.J. Andelman, M.I. Bakarr, L. Boitani, T.M. Brooks, R.M. Cowling et al. 2004. Effectiveness of the global protected area network in representing species diversity. Nature 428: 640-643.

Scholes, R.J. \& R. Biggs 2005. A biodiversity intactness index. Nature 434: 45-49.

TEEB 2010. The economics of ecosystems and biodiversity: Mainstraiming the Economics of Nature: A synthesis of the approach, conclusions and recommendations of TEEB.

Turner, W.R., K. Brandon, T.M. Brooks, R. Costanza, G.A.B. da Fonseca \& R. Portela 2007. Global Conservation of Biodiversity and Ecosystem Services. BioScience 57 (10): 868-873.

\section{Author}

\section{Zoltán Kun}

has a forestry technician degree and graduated as MSc Landscape Architect in Budapest, Hungary. His final thesis was about the linkage between floodplain restoration and landscape planning in Wageningen University, Netherlands. He worked for the WWF in Hungary in various positions. In 2002, he became executive director of PAN Parks Foundation.

zkun@panparks.org

More on the PAN Parks Foundation at http://www.panparks.org 